\title{
ROLE OF HUM TEST IN DIAGNOSIS OF HEARING LOSS
}

\author{
Dhakal $A^{1^{*}}$, Shrestha $B L^{2}$, Karmacharya $S^{3}$, Pradhan $A^{4}$
}

\begin{abstract}
Affiliation
1. Lecturer, Department of ENT-HNS, Dhulikhel Hospital- Kathmandu University Hospital, Dhulikhel, Kavre, Nepal

2. Associate Professor, Department of ENT-HNS, Dhulikhel HospitalKathmandu University Hospital, Dhulikhel, Kavre, Nepal

3. Final year resident, Department of ENT-HNS, Dhulikhel HospitalKathmandu University Hospital, Dhulikhel, Kavre, Nepal

4. Audiologist, Department of ENT-HNS, Dhulikhel HospitalKathmandu University Hospital, Dhulikhel, Kavre, Nepal
\end{abstract}

\section{ARTICLE INFO}

Received : 17 April, 2019

Accepted : 23 December, 2019

Published : 31 December, 2019

(C) Authors retain copyright and grant the journal right of first publication with the work simultaneously licensed under Creative Commons Attribution License CC - BY 4.0 that allows others to share the work with an acknowledgment of the work's authorship and initial publication in this journal.

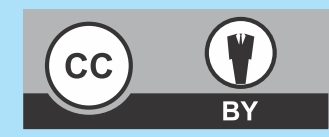

ORA 130

DOI: http://dx.doi.org/10.3126/bjhs.v4i3.27013

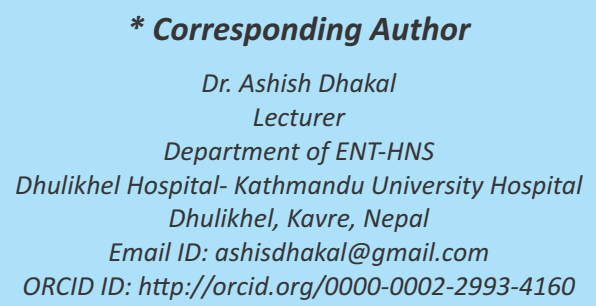

\section{Citation}

Dhakal A, Shrestha BL, Karmacharya S, Pradhan A. Role of Hum Test in Diagnosis of Hearing Loss. BJHS 2019;4 (3)10: 782-785.

\section{ABSTRACT}

\section{Introduction}

The Hum Test is used by some otolaryngologists as an alternative to the Weber Test to detect the presence and type of acute hearing change; however, its use has not yet been formally validated.

\section{Objective}

To compare the diagnostic performance of Hum test with Weber test to detect hearing loss taking pure tone audiometry as the gold standard.

\section{Methodology}

A prospective, cross-sectional study was conducted in the department of Otorhinolaryngology and Head and Neck surgery, Dhulikhel Hospital- Kathmandu University Hospital, from June 2018 to February 2019. Total of 257 patients were enrolled in the study and were subjected to 3 tests: Weber test, Hum test, and Pure tone audiometry.

\section{Result}

When examining patients with hearing loss, sensitivity of Hum test and weber test were $60.3 \%$ and $93.8 \%$ respectively. In patients with Conducting Hearing Loss (CHL), sensitivity of Hum test was $55.7 \%$, while Weber test was $94.8 \%$. In Sensorineural Hearing (SNHL), it was $74.6 \%$ for Hum test and $90.5 \%$ for Weber test. Likewise, according to laterality of disease, sensitivity of Hum test was $58.6 \%$ for unilateral hearing loss and $65.2 \%$ for bilateral hearing loss. For Weber test it was $96.3 \%$ for unilateral and $86.4 \%$ for bilateral disease.

\section{Conclusion}

Hum test is not as sensitive as Weber test in diagnosis of hearing loss both for conductive and sensorineural hearing loss.

\section{KEY WORDS}

Conductive hearing loss, hearing loss, Hum test, sensorineural hearing loss, tuning fork, Webertest 


\section{INDRODUCTION}

Hearing loss is a major health problem in developing countries around the world including Nepal. World Health Organization estimates that over 466 million people in the world are affected with disabling type of hearing loss $(6.1 \%$ of the world's population) out of which 432 million (93\%) of these are adults ( 242 million males, 190 million females) and 34 million (7\%) of these are children. ${ }^{1}$ The prevalence of disabling hearing loss for adults and children is greatest in South Asia followed by East Asia and Sub-Saharan Africa. ${ }^{2}$ Nepal is a developing country in South Asia and has been listed as one of the least developed nation by the United Nations. National census of Nepal 2011 AD (2068 BS) showed the hearing disability to be $15.45 \%$, out of which $1.94 \%$ total disability in the Nepalese population. $1.48 \%$ suffers with a combined hearing loss and vision impairment. Different types of speech problem was seen in $11.5 \%{ }^{3}$

Unless action is taken, it is likely that the number of people with disabling hearing loss will grow over the coming years. Projections show that the number could rise to 630 million by 2030 and may be over 900 million in $2050 .^{1}$

The Hum Test is a simple test which uses method of humming for diagnosis of hearing loss. The origin of use of this test in routine practice is not exactly known but it has been tried and used by some otolaryngologists for long. This test has been used as an alternative to the Weber Test to detect presence of hearing loss and type of acute change in the hearing status of patient. However, its use is not so popular due to limited research and validation. Hum Test has shown good diagnostic value in cases where a normal patient is subjected to sudden hearing loss. This consistent finding has helped in diagnosing cases when patient is remotely situated, and prompt referral and treatment cannot be carried out. ${ }^{4,5}$

Weber test is a tried and tested method of evaluation of type of hearing loss. It was demonstrated by Ernst Heinrich Weber in 1825, with patient reporting louder perception of sound in an ear with conductive hearing loss ( $\mathrm{CHL}$ ) when sound eliciting base of vibrating tuning fork was placed on the forehead. ${ }^{6}$ Since then it has been an important part in evaluation of hearing whether in middle ear disease or post ear surgery cases. This test has become widely used by clinicians' today. ${ }^{7-11}$ However, its validity and reliability has always been doubted by some clinicians and researchers. $7,8,12,13$

The Hum Test may also be helpful in assessing hearing status immediately following surgery in the recovery unit where tuning forks are typically not readily available. ${ }^{10,14}$ Studies have shown it to be comparable to the Weber Test with regards to its sensitivity, specificity and diagnostic accuracy in assessing new onset unilateral $\mathrm{CHL}$ or sensorineural hearing loss (SNHL) in previously normal hearing subjects. ${ }^{5,15}$

The aim of this study is to compare between the accurateness of Hum test and Weber test against that of Pure tone audiometry (PTA). This would help to find out whether Hum test could be used in identification of types of hearing loss.

\section{METHODOLOGY}

This was a prospective, cross-sectional study conducted in the department of Otorhinolaryngology and Head and Neck surgery from June 2018 to February 2019. Approval from Institutional Review Committee of Kathmandu University School of Medical Sciences, Dhulikhel Hospital was taken, and informed consent was obtained from the patients.

Patient presenting with hearing loss to the out-patient department were enrolled in the study. They were tested to evaluate the performance of Hum test in comparison to Weber test, keeping PTA as gold standard. All patients were subjected to 3 tests: Weber test, Hum test, and PTA.

For Weber test, a $512 \mathrm{~Hz}$ aluminum tuning fork was used. Tine of the tuning fork was stroked on the elbow to produce sound and then its base was placed onto the subject's forehead in midline for 2 to 4 seconds. Patient was then asked if the sound appeared to be central or lateralized. A $512 \mathrm{~Hz}$ tuning fork was used instead of $256 \mathrm{~Hz}$ as it has a lower false positive rate. ${ }^{14}$

For the Hum Test, examiner first demonstrated the test with mid-range monotone " $\mathrm{hmmmmmm}$ " sound of 2-3 second duration at intensity slightly softer than casual conversation. Then patient was asked to repeat similar procedure. The patient was then asked if the sound was more pronounced on the right, left or perceived equally. Retest was performed to confirm the reproducibility of response. If different response was seen in retest, test was done 3 times and recurring response was taken.

Lateralization of the Weber and Hum Test was categorized as right, left, or central/ equal. As a rule of thumb, the tone is heard centrally in patient with normal hearing or with equal hearing loss in both ears. In asymmetric/unilateral hearing loss, the tone lateralizes to one side. It is further interpreted as lateralization to ear with hearing loss in cases of conductive hearing loss; and to the side with better hearing in sensorineural hearing loss.

PTA was then performed using Midimate 602, diagnostic audiometer (Madsen electronics company) in sound treated double room set up. The PTA measurements included air conduction $(\mathrm{AC})$ and bone conduction $(\mathrm{BC})$ thresholds from $500 \mathrm{~Hz}$ to $8 \mathrm{kHz}$ for both ears. Hearing threshold and type of hearing loss was calculated as per WHO classification. Threshold of hearing loss was calculated taking average of AC threshold in 500, 1000 and $2000 \mathrm{~Hz}$. Type of hearing loss was then assessed. $\mathrm{CHL}$ was labeled for patient with airbone gap $(A B G)>10 \mathrm{~dB}$ and $A C$ threshold $>25 d B$. Patients were labelled as SNHL when both $A C$ and $B C$ curve threshold $>25 \mathrm{~dB}$ and $\mathrm{ABG}<10 \mathrm{~dB}$. $^{14,19}$

All three (3) tests were performed during the same session for each patient.

Inclusion criteria were: All age, both gender presenting with hearing loss planned for hearing evaluation.

Exclusion criteria were: Patient with mixed type of hearing loss, patient unwilling to take part in the study and patients who were unable to respond to both Weber and Hum test. 
The sensitivity of Hum test and Weber test were then calculated taking the value from PTA as gold standard. These values were then compared and analyzed.

\section{RESULT}

Total of 257 patients were enrolled in the study with age ranging from 9-85 years (mean age of $32.62+-15.4$ years). There were total 137 male (53.3\%) and 120 females (46.7\%) in the study (Table 1).

Table 1: Patient demographics
\begin{tabular}{|l|c|}
\hline Variable & Frequency (N=257) \\
\hline Gender & $137(53.3 \%)$ \\
Male & $120(46.7 \%)$ \\
Female & $32.62+-15.4$ \\
\hline Age (years)
\end{tabular}

Using PTA as gold standard, diagnostic data for Weber test and Hum test were compared. For Weber test the sensitivity was241 (93.8\%) and for Hum test it was 102 (60.3\%) (Figure 1).

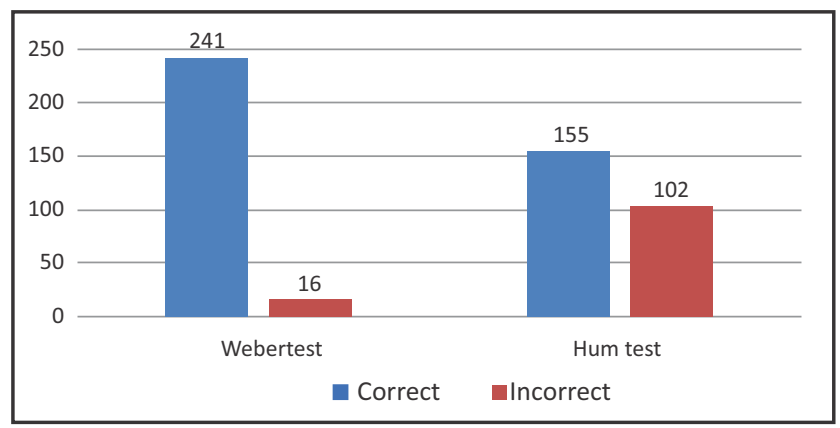

In patients with $\mathrm{CHL}$, sensitivity of Weber test was $94.8 \%$ while Hum test was $55.7 \%$. In SNHL, it was $90.5 \%$ for Weber and $74.6 \%$ for Hum test. Likewise, according to laterality of disease, sensitivity of Weber test was $96.3 \%$ for unilateral hearing loss and $86.4 \%$ for bilateral hearing loss. In case of Hum test the sensitivity was $58.6 \%$ for unilateral and $65.2 \%$ for bilateral disease (Table 2).

\begin{tabular}{|c|c|c|c|c|c|}
\hline & & CHL & SNHL & $\begin{array}{l}\text { Unilateral } \\
\text { disease }\end{array}$ & $\begin{array}{l}\text { Bilateral } \\
\text { disease }\end{array}$ \\
\hline \multirow[t]{3}{*}{ Weber test } & Correct & 184 & 57 & 184 & 57 \\
\hline & Incorrect & 10 & 6 & 7 & 9 \\
\hline & Sensitivity & $94.8 \%$ & $90.5 \%$ & $96.3 \%$ & $86.4 \%$ \\
\hline \multirow[t]{3}{*}{ Hum test } & Correct & 108 & 47 & 112 & 43 \\
\hline & Incorrect & 86 & 16 & 79 & 23 \\
\hline & Sensitivity & $55.7 \%$ & $74.6 \%$ & $58.6 \%$ & $65.2 \%$ \\
\hline
\end{tabular}

\section{DISCUSSION}

Hearing loss is a major public health burden in developing countries like Nepal. The prevalence of adult hearing impairment substantially higher in middle and low income countries than high-income countries. ${ }^{16}$ WHO estimates 38,000 deaf children are born every year in South East Asian Region. $^{17,18}$ The pattern of hearing loss may vary from community to community, place to place, one geographic region to other and from hospital to hospital. Knowledge of pattern of hearing loss can help health personnel to make the proper diagnosis and treatment as per requirement. Such study helps in timely detection of the disease and treatment, ultimately will help in reducing morbidity and improve quality of life.

Hearing loss may be mild, moderate and severe to profound. It can affect one or both ears. Hearing loss can lead to social isolation and stigma, loneliness, embarrassment, depression, psychiatric disturbance, relationship difficulties, restricted career choices, relatively low earnings and occupational stress. ${ }^{2}$

For the diagnosis of hearing loss, PTA is a simple gold standard diagnostic tool performed in day to day practice by the audiologists as per referred by the otorhinolaryngologists. PTA is easy to perform and gives valuable information regarding type, configuration of hearing loss and further management planning. ${ }^{19}$

Hum test is an easy and cost-free method of evaluation of hearing of patient which can be done in setting where ENT setup is absent or in cases where patient need evaluating himself regarding status of his hearing. Researches demonstrating the accuracy of this test are scarce, so we did this study to find its implication and accuracy in our setup.

In our study, based on PTA evaluation of 257 patients with either CHL or SNHL, Hum test was able to correctly identify in 155 cases with sensitivity of $60.3 \%$. This result is far below the correct lateralization shown in 241 cases with Weber test (sensitivity 93.8\%).

In patients with $\mathrm{CHL}$, sensitivity of Weber test was $94.8 \%$ while Hum test was $55.7 \%$. The result of weber test is similar to that of recent studies done by Miltenberg et al, Bagai et al, lacovidou et al and Shuman et al but result for Hum test is in contrast to the results shown by Brown and Ahmed et al. , $9-11,15^{-15}$

In SNHL, Hum test showed better results (74.6\% sensitivity) than in cases with $\mathrm{CHL}$ which is similar to that shown by Brown.

Studies done by Bagai et al, Ahmed et al suggested increase in false result in bilateral disease cases which we didn't find., ${ }^{9,15}$ In this study there was not a drastic difference in sensitivity between patients with unilateral or bilateral hearing loss. For Hum test it was $58.6 \%$ and $65.2 \%$ and for Weber test $96.3 \%$ and $86.4 \%$ respectively.

\section{CONCLUSIONS}

Hearing impairment is one of the major health problems in a country like Nepal where ear diseases attributing to hearing loss are common. But in our context, the diagnosis is usually delayed until certain degree of hearing loss occurs. Improvement in health care delivery system and awareness programs can help in early diagnosis, treatment and rehabilitation of hearing impairment. More ideas and researches should be guided towards formulating methods which could help in identifying hearing loss without use of sophisticated instruments and skilled manpower.

Our study showed that Hum test is not as sensitive as Weber 
test in diagnosis of hearing loss in conductive and sensorineural hearing loss. Despite of these facts, in situations where tuning fork is not available, this test can be used as a screening tool for assessing general population.

\section{RECOMMENDATIONS}

We do not recommend the use of Hum test as a primary test for hearing assessment in general hospital setup. Apart from that, in situations where hearing assessment equipments are not available, this test can be used for screening purposes. Also, in cases where disease requires serial monitoring of hearing for fluctuation, this can be used.

\section{LIMITATIONS OF THE STUDY}

a) The procedure of humming is a subjective task and is thus liable to variability in pitch and frequency from subject to subject during assessment; b) The included cases were of hearing loss and normal subjects were not included in this study, so specificity and predictive values of the tests could not be calculated.

\section{ACKNOWLEDGEMENTS}

The authors would like to thank Dr Pratiksha Pathak for her help in reviewing the article preparation and review.

\section{CONFLICTS OF INTEREST}

The authors declare that there is no conflict of interest regarding the publication of this paper.

\section{FINANCIAL DISCLOSURE}

The authors didn't receive any funding for the study.

\section{REFERENCES}

1. WHO | Estimates [Internet]. WHO. [cited 2019 Apr 23]. Available from: http://www.who.int/deafness/estimates/en/

2. WHO | The global burden of disabling hearing impairment: a call to action [Internet]. WHO. [cited 2019 Apr 23]. Available from: https://www.who.int/bulletin/volumes/92/5/13-128728/en/

3. National Population and Housing Census 2011(National Report) Central Bureau of Statistics [Internet]. [cited 2019 Apr 23]. Available from: https://cbs.gov.np/national-population-and-housing-census2011national-report/

4. Behn A, Westerberg BD, Zhang H, Riding KH, Ludemann JP, Kozak FK. Accuracy of the Weber and Rinne tuning fork tests in evaluation of children with otitis media with effusion. J Otolaryngol. 2007 Aug;36(4):197-202. PMID: 17942032

5. Brown J. Humming test for conductive hearing loss. The Lancet. 1995 Jul 8;346(8967):128. PMID: 7603203

6. Bickerton RC, Barr GS. The origin of the tuning fork. J R Soc Med. 1987 Dec;80(12):771-3. PMID: 3323515

7. Tonndorf J. Bone conduction. Studies in experimental animals. Acta Otolaryngol (Stockh). 1966;Suppl 213:1.PMID: 5934763

8. Miltenburg DM. The validity of tuning fork tests in diagnosing hearing loss. J Otolaryngol. 1994 Aug;23(4):254-9. PMID: 7996624

9. Bagai $A$, Thavendiranathan $P$, Detsky AS. Does this patient have hearing impairment? JAMA. 2006 Jan 25;295(4):416-28. PMID: 16434632. DOI:10.1001/jama.295.4.416

10. Iacovidou A, Giblett N, Doshi J, Jindal M. How reliable is the "scratch test" versus the Weber test after tympanomastoid surgery? Otol Neurotol Off Publ Am Otol Soc Am Neurotol Soc Eur AcadOto INeurotol. 2014 Jun;35(5):762-3. PMID:24643030. DOI:10.1097/ MAO.0000000000000357
11. Shuman AG, Li X, Halpin CF, Rauch SD, Telian SA. Tuning fork testing in sudden sensorineural hearing loss. JAMA Intern Med. $2013 \mathrm{Apr}$ 22;173(8):706-7. PMID:23529707. DOI:10.1001/ jamainternmed. 2013.2813

12. Stankiewicz JA, Mowry HJ. Clinical accuracy of tuning fork tests. The Laryngoscope. 1979 Dec;89(12):1956-63. PMID:513917. DOI:10. 1288/00005537-197912000-00009

13. Haapaniemi JJ, Suonpää JT, Salmivalli AJ, Virolainen ES. C1-tuning fork tests in school-aged children. Auris Nasus Larynx. 1996;23:26-32. PMID:8809320

14. Chole RA, Cook GB. The Rinne test for conductive deafness. A critical reappraisal. Arch Otolaryngol Head Neck Surg. 1988 Apr;114(4): 399-403. PMID:3348896

15. Ahmed OH, Gallant SC, Ruiz R, Wang B, Shapiro WH, Voigt EP. Validity of the Hum Test, a Simple and Reliable Alternative to the Weber Test. Ann OtolRhinolLaryngol. 2018 Jun;127(6):402-5. PMID:29776326. DOI:10.1177/0003489418772860

16. Stevens G, Flaxman S, Brunskill E, Mascarenhas M, Mathers CD, Finucane $\mathrm{M}$, et al. Global and regional hearing impairment prevalence: an analysis of 42 studies in 29 countries. Eur J Public Health. 2013 Feb;23(1):146-52. PMID:22197756. DOI: 10.1093/ eurpub/ckr176

17. Monteiro de Castro Silva I, Feitosa MAG. High-frequency audiometry in young and older adults when conventional audiometry is normal. Braz J Otorhinolaryngol. 2006 Oct;72(5):665-72. PMID:17221060

18. Akhtar N, Datta PG, Alauddin M, Kamal N. Neonatal hearing screening. Bangladesh J Otorhinolaryngol. 2010;16(1):54-9. DOI: 10.3329/bjo.v16i1.5782

19. Kelly EA, Li B, Adams ME. Diagnostic Accuracy of Tuning Fork Tests for Hearing Loss: A Systematic Review. Otolaryngol-Head Neck Surg Off J Am AcadOtolaryngol-Head Neck Surg. 2018 Aug;159(2):220-30. PMID:29661046. DOI: 10.1177/0194599818770405 